\title{
Gambogic Acid Efficiently Kills Stem-Like Colorectal Cancer Cells by Upregulating ZFP36 Expression
}

\author{
Fang Wei $\mathrm{j}^{\mathrm{a}, \mathrm{b}}$ Tong Zhang ${ }^{\mathrm{a}, \mathrm{b}}$ Zhi Yang ${ }^{\mathrm{a}, \mathrm{b}}$ Jian-Chang Wei ${ }^{\mathrm{a}, \mathrm{b}}$ Hong-Fen Shen ${ }^{\mathrm{c}}$ \\ Dong Xiaoc Qiang Wang ${ }^{a, b}$ Ping Yang ${ }^{a, b}$ Hua-Cui Chen ${ }^{a, b}$ \\ $\mathrm{He} \mathrm{Hu}^{\mathrm{a}, \mathrm{b}}$ Zhuan-Peng Chen ${ }^{\mathrm{a}, \mathrm{b}}$ Qing Huanga ${ }^{\mathrm{a} b \mathrm{~b}}$ Wang-Lin Lia, Jie Cao ${ }^{\mathrm{a}, \mathrm{b}}$ \\ aGuangzhou Digestive Disease Center, Guangzhou First People's Hospital, Guangzhou Medical \\ University, Guangzhou, 'buangzhou Digestive Disease Center, Guangzhou First People's Hospital, \\ the Second Affiliated Hospital, South China University of Technology, Guangzhou, 'Cancer Research \\ Institute, Southern Medical University, Guangzhou, China
}

\section{Key Words}

Colorectal carcinoma • Gambogic acid • Cancer stem cells • Promoter-reporter gene strategy -ZFP36 • In vivo bioluminescence imaging

\begin{abstract}
Background/Aims: Gambogic acid (GA), the main active compound of Gamboge hanburyi, has been reported to be a potential novel antitumor drug. Whether GA inhibits putative cancer stem cells (CSCs), which are considered to be the major cause of cancer treatment failure, remains largely unknown. This study investigated whether GA inhibits the CSCs of colorectal cancer (CRC) and its possible mechanisms. Methods: We performed CCK8 and tumor sphere formation assays, percentage analysis of both side population and $\mathrm{CD} 133^{+} \mathrm{CD} 44^{+}$cells, and the detection of stem cells markers, in order to assess the role of GA in inhibiting the stem celllike features of CRC. An mRNA microarray was performed to identify the downstream gene affected by GA and rescue assays were performed to further clarify whether the downstream gene is involved in the GA induced decrease of the stem cell-like CRC population. CRC cells were engineered with a CSC detector vector encoding GFP and luciferase (Luc) under the control of the Nanog promoter, which were utilized to investigate the effect of GA on putative CSC in human tumor xenograft-bearing mice using in vivo bioluminescence imaging. Results: Our results showed that GA significantly reduced tumor sphere formation and the percentages of side population and $\mathrm{CD} 133^{+} \mathrm{CD} 44^{+}$cells, while also decreasing the expression of stemness and EMT-associated markers in CRC cells in vitro. GA killed stem-like CRC cells by upregulating the expression of ZFP36, which is dependent on the inactivation of the EGFR/ ERK signaling pathway. GFP + cells harboring the $\mathrm{P}_{\text {Nanog }}$-GFP-T2A-Luc transgene exhibited CSC characteristics. The in vivo results showed that GA significantly inhibited tumor growth in nude mice, accompanied by a remarkable reduction in the putative CSC number, based on whole-
\end{abstract}

F. W ei, T. Zhang, Z. Yang, J.-C. Wei contributed equally to this work.

Wang-Lin Li

and Jie Cao

\section{KARGER}

Guangzhou Digestive Disease Center, Guangzhou First People's Hospital,

Guangzhou Medical University, Guangzhou (China)

E-Mail liwanglin1974@126.com, czhongt@126.com 
body bioluminescence imaging. Conclusion: These findings suggest that GA significantly inhibits putative CSCS of CRC both in vitro and in vivo by inhibiting the activation of the EGFR/ ERK/ZFP36 signaling pathway and may be an effective drug candidate for anticancer therapies.

(C) 2018 The Author(s)

Published by S. Karger AG, Basel

\section{Introduction}

Colorectal cancer (CRC) is one of the most common cancers worldwide [1]. While local resection is an effective approach for CRC therapy, distant metastases are still a major issue in its treatment $[2,3]$. Therefore, the identification of novel and effective therapies against CRC is urgently needed.

Gambogic acid ( $\mathrm{GA}, \mathrm{C}_{38} \mathrm{H}_{44} \mathrm{O}_{8}$ ) is a polyprenylated xanthone and one of the main active compounds of Gamboge hanburyi (a traditional Chinese medicine), which has been used for thousands of years for detoxification, maintenance of homeostasis, anti-inflammation, and as a parasiticide [4]. GA has been proven to have anti-tumor effects in many tumor types [5, 6]. Recent reports suggest that the molecular mechanisms underlying the anti-tumor effects of GA include inducing apoptosis and cell cycle arrest, as well as the inhibition of telomerase activity, angiogenesis, and the invasion and metastasis of tumor cells [7-11].

Cancer stem cells (CSCs) play an essential role in tumor initiation, metastasis, and relapse. CSCs are therefore considered to be the primary cause of tumor treatment failure, due to their resistance to conventional therapies [12-14]. Therefore, inhibiting the growth of tumoral CSCs is critically important for cancer treatment. In this study, we investigated the effects of GA on the growth of CRC CSCs, both in vitro and in vivo. Our study may provide a novel approach for the effective treatment of CRCs.

\section{Materials and Methods}

CRC cell lines

The human CRC cell lines HCT116 and SW480 were cultured in RPMI 1640 medium supplemented with $10 \%$ fetal bovine serum (FBS) in a humidified incubator with $5 \% \mathrm{CO}_{2}$ at $37^{\circ} \mathrm{C}$.

\section{CCK8 assay and colony formation assay}

The tumor-killing activity of Gambogic acid (GA, Sigma) against CRC cells was assessed using a CCK8 assay. Briefly, HCT116 and SW480 cells were plated in 96-well plates at $5 \times 10^{3}$ cells/well. GA was added after the CRC cells had adhered at the final concentrations $(0,0.125,0.25,0.5,1,2$, or $3 \mu \mathrm{M})$ and were incubated for $24 \mathrm{~h}, 48 \mathrm{~h}$, or $72 \mathrm{~h}$. The inhibition rate was calculated according to the following formula. Inhibition rate $(100 \%)=1-[$ (A value in experimental well) / (A value in target cell wells) $] \times 100 \%$. After CRC cells were incubated with GA at different concentrations $(0,0.5$, or $1 \mu \mathrm{M})$ for $24 \mathrm{~h}$, cells were washed with PBS, and used for the colony formation assay. The assay was performed in triplicate.

\section{Tumor spheroid formation assay}

After CRC cells were treated with GA at different concentrations $(0,0.5$, or $1 \mu \mathrm{mol})$ for $24 \mathrm{~h}$, cancer cells were harvested and counted for the tumor spheroid formation assay. Next, 10, 000 CRC cells were plated in 6-well ultralow attachment plates (Corning, Corning, NY) in serum-free DMEM-F12 (Hyclone), supplemented with epidermal growth factor (20ng/mL, Peprotech), basic fibroblast growth factor (10ng/ mL, Peprotech), and B27 (1:50 dilution; BD). After one week of incubation, the tumor spheres were counted under a microscope. The experiment was performed in triplicate.

Percentages of side population cells (SP cells) analyzed by flow cytometry

SW480 cells were co-cultured at different GA concentrations $(0,0.5$, or $1 \mu \mathrm{mol})$ for $24 \mathrm{~h}$, and CRC cells were then washed and digested with $0.25 \%$ trypsin, washed twice with PBS, and resuspended in RPMI1640 medium (supplemented with $2 \%$ FBS) at a concentration of $5 \times 10^{5}$ cells $/ \mathrm{mL}$. The DNA binding Hoechst 33342 dye (Sigma, USA) was added and the cells were incubated at $37^{\circ} \mathrm{C}$ in a $5 \% \mathrm{CO}_{2}$ incubator for 90 min 


\section{Cellular Physiology Cell Physiol Biochem 2018;46:829-846

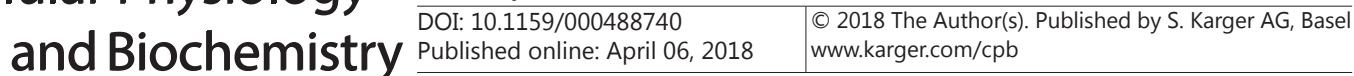 \\ Wei et al.: GA Kills Colorectal Cancer Stem Cells}

in the dark with periodic mixing. The cells were again washed twice with PBS, $1 \mathrm{mg} / \mathrm{mL}$ propidium iodide (Sigma, USA) was added, and the cells were maintained at $4{ }^{\circ} \mathrm{C}$ in the dark prior to flow cytometry analysis (BD FACSAria). All samples were assayed in triplicate.

Percentages of $C D 133^{+} / C D 44^{+}$cells by flow cytometry

The $\mathrm{CD} 133^{+} / \mathrm{CD}_{4} 4^{+}$cell ratio was analyzed by FACS, according to the manufacturer's protocol (MACS Miltenyi Biotec). The cells were treated with GA, then washed and resuspended in PBS. Next, $10 \mu \mathrm{l}$ of the CD133/1 (AC133)-PE and 10 $\mu \mathrm{l} \mathrm{CD44-FITC} \mathrm{antibodies} \mathrm{were} \mathrm{added} \mathrm{per} 100 \mathrm{ml}$ of suspension, and the suspension was mixed well and incubated for 20 minutes in the dark at $4^{\circ} \mathrm{C}$. Finally, after two more washes, the cell pellet was resuspended in $400-500 \mu l$ buffer for flow cytometry analysis. All samples were assayed in triplicate.

CD133-PE and CD44-FITC antibody labeling of cancer cells and sorting of cell populations

HCT116 and SW480 cells were labeled using CD133-PE and CD44-FITC antibodies, as described above. $\mathrm{CD} 133^{+} / \mathrm{CD}_{4} 4^{+}$fractions and non-CD133 ${ }^{+} / \mathrm{CD} 44^{+}$fractions were sorted for subsequent tumor-killing activity by fluorescence-activated cell sorting (FACS) (BD FACSAria). All samples were assayed in triplicate.

RNA isolation and quantitative real-time PCR ( $q R T-P C R$ )

Total RNA was extracted from the colorectal cancer cells using the Trizol reagent (TaKaRa) and reversely transcribed into cDNA using the PrimeScript RT reagent Kit (TaKaRa), according to the manufacturer's instructions. We analyzed mRNA expression with qRT-PCR on a Stratagene Mx3005P qRT-PCR system using the SYBR Green qRT-PCR master mix (TaKaRa) and GAPDH for normalization. All samples were normalized to the internal controls and the fold changes were calculated through relative quantification $\left(2^{-\Delta \Delta c t}\right)$. Three independent experiments were carried out.

Western blot analysis and antibodies

Protein lysates were separated by sodium dodecyl sulfate polyacrylamide gel electrophoresis (SDSPAGE), and transferred to a polyvinylidene difluoride (PVDF) membrane. The blots were probed with the indicated primary antibodies ( $\beta$-catenin, BD Biosciences, 1:1000), (Vimentin, BD Biosciences, 1:1000), (Bmi-1, Abcam, 1:1000), (ALDH1, Abcam, 1:1000), (Oct4, Abcam, 1:1000), (Nanog, Abcam, 1:1000), (ABCG2, Abcam, 1:1000), (ZFP36, SANTA CRUZ, 1:1000), (EGFR, Cell Signaling Technology, 1:1000), (p-EGFR, Cell Signaling Technology, 1:1000), (ERK1/2, ABclonal, 1:1000), (p-ERK1/2, ABclonal, 1:1000), followed by HRP (horseradish peroxidase)-labeled secondary antibody. The hybridization signal was detected using enhanced chemiluminescence (ECL) (Cat.No:KGP1122, KeyGEN BioTECH). GAPDH was used as the loading control.

Transwell migration assay and Boyden invasion assay

After CRC cells were treated with different concentrations of GA for $24 \mathrm{~h}$, the cancer cells were collected and counted for the Transwell migration and Boyden invasion assays, as previously described [15]. Three independent experiments were carried out.

mRNA microarray analysis

RNA from SW480 cells with and without GA treatment was extracted with a total RNA isolation kit (Agilent). The microarray expression profiles were collected using Affymetrix PrimeView ${ }^{\mathrm{TM}}$ Human Gene Expression Array.

\section{Lentivirus plasmids}

The pLV-shZFP36-EGFP plasmid was purchased from Gene Copoeia. The pLV-P ${ }_{\text {Nanog }}$-GFP-T2A-Luc plasmid housed the reporter genes [i.e., GFP and luciferase (Luc)] under the control of Nanog promoter, the puromycin resistance gene under the control of the EF-1 $\alpha$ promoter, and the lentiviral packaging plasmids psPAX2 and pMD2.G, all of which were kindly provided by Prof. Dong Xiao (Southern Medical University, China).

Lentivirus production and transduction

In order to generate stable cell lines, recombinant lentiviruses (LV-shZFP36-EGFP and LV-P ${ }_{\text {Nanog }}$ GFPT2A-Luc) were generated as previously described [16] and were used to infect HCT116 and SW480 cells. Next, 


\section{Cellular Physiology Cell Physiol Biochem 2018;46:829-846 and Biochemistry Published online: April 06, $2018 \quad \begin{aligned} & \text { DOI 1015/2018 The Author(s). Published by S. Karger AG, Basel } \\ & \text { www.karger.com/cpb }\end{aligned}$ \\ Wei et al.: GA Kills Colorectal Cancer Stem Cells}

stable infected cells were selected with puromycin at a $4 \mu \mathrm{g} / \mathrm{ml}$ concentration to establish the puromycinresistant stable reporter cell line (HCT116 and SW480 cells) carrying the $\mathrm{P}_{\text {Nanog }}$-GFP-T2A-Luc transgene, followed by a GFP assay with an inverted fluorescence microscope (Nikon, Japan) and flow cytometry (BD FACSAria). GFP+ and GFP- fractions were then sorted for subsequent experiments by fluorescence-activated cell sorting (FACS) (BD FACSAria).

\section{Xenograft experiments in nude mice}

The animal experiments were carried out in strict accordance with the recommendations in the Guide for the Care and Use of Laboratory Animals of Guangzhou Medical University. The animal protocol was approved by the Ethics Committee for Animal Experiments of Guangzhou Medical University. Nude mice were purchased from the Medical Laboratory Animal Center of Guangdong Province, and were maintained in microisolator cages under aseptic conditions. HCT116 cells $\left(1 \times 10^{6}\right.$ cells) harboring the $\mathrm{P}_{\text {Nanog }}$-GFPT2A-Luc transgene were resuspended in a mix of PBS and BD Matrigel (BD Biosciences) (1:1), and then subcutaneously injected into the right dorsal thigh of each mouse. One week after HCT116 cell implantation, the mice were treated daily with GA $(1 \mathrm{mg} / \mathrm{kg}$ ) or PBS, for the untreated control, via intraperitoneal injection. Tumor growth was determined by caliper measurement or in vivo bioluminescence (BLI) (see below). Tumor growth was monitored with calipers and the volume was calculated using the formula, $V=\left(L \times l^{2}\right) / 2$, where $\mathrm{L}$ is the length and $\mathrm{l}$ is the diameter width of the tumor. Twenty days after cancer cell implantation, mice were sacrificed, tumors were dissected, weighed, and fixed overnight in $4 \%$ paraformaldehyde, dehydrated, paraffin-embedded, and sectioned. All surgery was performed under sodium pentobarbital anesthesia, and all efforts were made to minimize the suffering of animals.

\section{In vivo bioluminescence imaging}

The protocols for whole-animal bioluminescence imaging to noninvasively detect Luc activity using the Xenogen IVIS Lumina II Imaging System (Xenogen Corp., Alameda, CA, USA) have been previously described [17].

\section{Histological and immunohistological examinations and antibodies}

For histology analysis, tumor tissues were fixed with 4\% paraformaldehyde (PFA) in PBS, embedded in paraffin, cut into $5 \mu \mathrm{m}$ thick sections, and then deparaffinized, followed by hematoxylin and eosin staining (H\&E staining) according to standard procedures. After deparaffinization and rehydration, the paraffinembedded sections were exposed to high pressure for $2 \mathrm{~min}$ for antigenic retrieval. The slides were then incubated overnight at $4^{\circ} \mathrm{C}$ with the indicated primary antibodies (Nanog, Abcam, 1:50), (Ki67, Abcam, 1:50), (ZFP36, SANTA CRUZ, 1:50), (p-EGFR, Cell Signaling Technology, 1:50), (ERK1/2, ABclonal, 1:50).

\section{Statistical analysis}

Data are presented as mean \pm SD. Statistical analysis was performed using the SPSS 13.0 software package and Graphpad 5.0. An independent-sample t-test was used for comparisons of 2 independent groups. One-Way ANOVA was used to compare multiple groups. The mixed model analysis of variance (TwoWay ANOVA) was employed to assess the GA cytotoxic activity curves in vivo. Statistical significance was assessed as ${ }^{*} P<0.05$ and ${ }^{*} P<0.01$.

\section{Results}

\section{Gambogic acid inhibited CRC cell growth}

The anti-tumor activity of GA against the CRC HCT116 and SW480 cell lines was first evaluated using the CCK8 assay. As shown in Fig. 1A and B, GA inhibited the growth of HCT116 and SW480 cells in a dose-dependent manner. The colony formation assay also showed that GA treatment resulted in fewer colonies in a concentration dependent manner compared with the control group (Fig. 1C). Taken together, these results suggest that GA significantly inhibited the growth of CRC cells. 
Fig. 1. Evaluation of the tumor killing activity of GA in vitro. (A-B) The proliferation ability of HCT116 and SW480 cells treated with GA was analyzed with a CCK8 assay. (C) Colony formation assay for HCT116 and SW480 cells treated with GA.

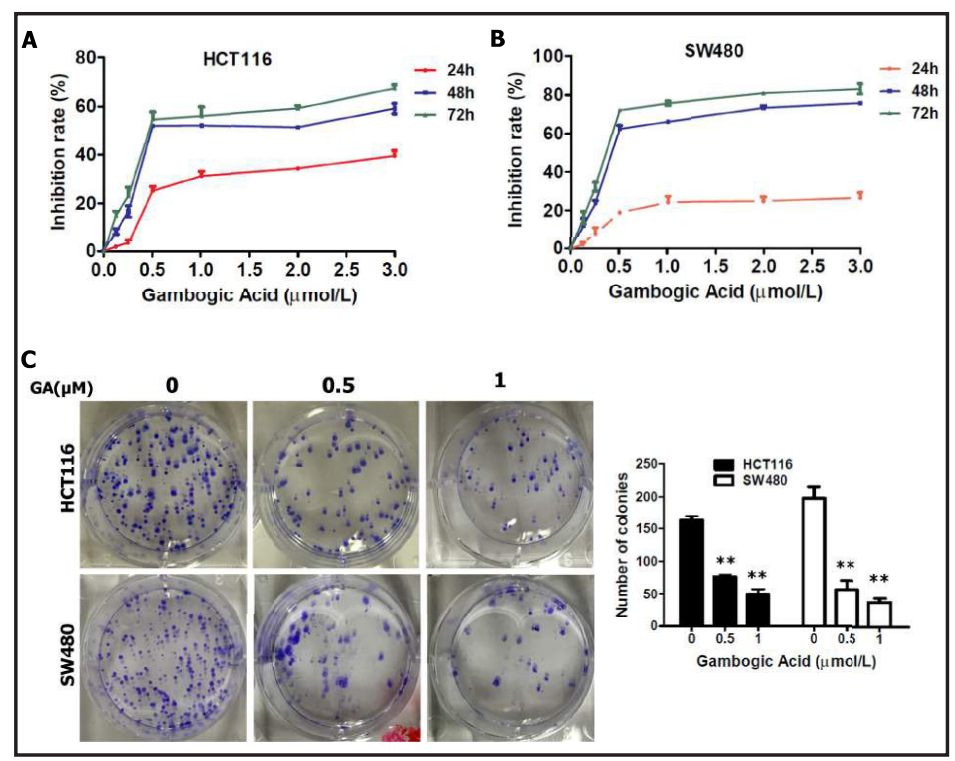

GA decreased the stem cell-like population in CRC cells

Previous studies have reported that cancer stem cells can form tumor spheres in serumfree, non-adherent conditions in vitro, and that they can even become enriched in this condition [18]. Therefore, we examined the ability of HCT116 and SW480 cells to form tumor spheres after treatment with different concentration of GA by using an in vitro tumor sphere formation assay. The results showed that there was a dramatic decrease in the number of tumor spheres in GA treated CRC cells compared to the control group (Fig. 2A).

Side populations (SPs) and CD133 ${ }^{+} \mathrm{CD} 44^{+}$cells have also been reported to exhibit cancer stem cell characteristics [19-21]. We further examined the effect of GA treatment on the percentages of stem cell-like SP cells in SW480 cells, and found that GA treatment sharply decreased the size of the SP cells in the SW480 cell line (from 3.6\% to 0.8\%) (Fig. 2C). As shown in Fig. 2B, GA treatment dramatically reduced the percentages of $\mathrm{CD} 133^{+} \mathrm{CD} 44^{+}$cells in the HCT116 cell culture. Together, our results indicate that GA treatment can remarkably reduce the cancer stem-like cell population of CRC cells.

In order to separately evaluate the tumor-killing activity of GA against $\mathrm{CD} 133^{+} \mathrm{CD} 44^{+}$cells (putative CSCs) and non-CD133 ${ }^{+} \mathrm{CD} 44^{+}$cells, we sorted $\mathrm{CD} 133^{+} \mathrm{CD} 44^{+}$and nonCD $133^{+} \mathrm{CD} 44^{+}$cells by flow cytometry. Our results showed that the antitumor activity of GA remained equally effective against both $\mathrm{CD} 133^{+} \mathrm{CD} 44^{+}$and non-CD $133^{+} \mathrm{CD} 44^{+}$cells (Fig. 2D), The IC50 between $\mathrm{CD} 133^{+} \mathrm{CD} 44^{+}$and non-CD $133^{+} \mathrm{CD} 44^{+}$cells is not statistically significant,

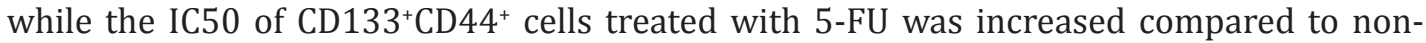
$\mathrm{CD} 133^{+} \mathrm{CD} 44^{+}$cells (Fig. 2E). This finding illustrates that the tumor-killing activity of GA was equally intense against putative CSCs and non-CSCs of CRC cells, and GA was more effective than 5-FU chemotherapy.

GA treatment reduced the expression of stemness-related genes in CRC cells

CSC-related genes (i.e., Nanog, Oct4, Sox2, ALDH1, and Bmi-1) have frequently been used to identify CSC populations from clinical samples and various cancer cell lines. In order to evaluate the effect of GA treatment on stemness-related gene expression in CRC cells, representative stem cell markers were analyzed with both qRT-PCR and western blot. Fig. $3 \mathrm{~A}$ demonstrates a dramatically decreased expression of stemness-associated genes (i.e., Nanog, Oct4, Sox2, ALDH1, CD133, and Bmi-1) observed at the transcriptional level in the GA group compared with the control. The decreased expression of stemness-related genes was further verified at the protein level (Fig. 3B), further illustrating that GA treatment significantly reduced stemness-related gene expression in CRC cells. 
Fig. 2. GA significantly inhibited stem cell-like cancer cells of CRC. (A) Images showing tumor sphere formation in GA-treated CRC cells. (B) GA treatment resulted in the decreased size of $\mathrm{CD} 133^{+} \mathrm{CD} 44^{+}$ cells. (C) GA treatment led to the decreased percentage of SP cells. (D) The antitumor activity of GA was equally intense against $\mathrm{CD} 133^{+} \mathrm{CD} 44^{+}$ and non-CD $133^{+} \mathrm{CD} 44^{+}$CRC cells. (E) The CSCs drug resistance was estimated by the IC50 assay. non-CD $133^{+} \mathrm{CD} 44^{+}$cells cultured on conventional rigid plates and $\mathrm{CD}_{133}{ }^{+} \mathrm{CD} 44^{+}(5 \times$ $10^{3}$ ) were seeded into 96-well plates. Different concentrations of GA or 5-FU were added to the experimental group. $48 \mathrm{~h}$ later, the cells were collected and subjected to the CCK8 assay.

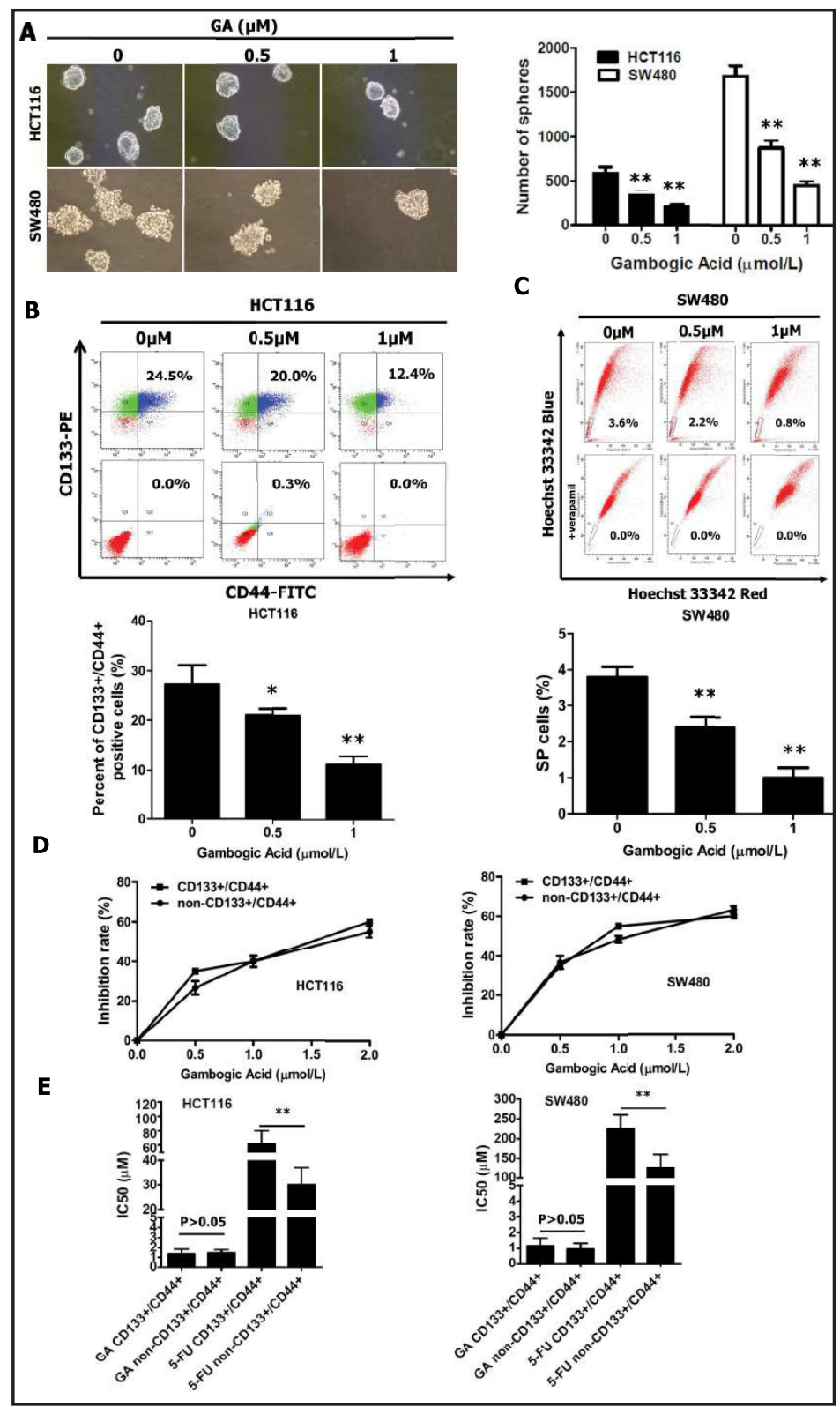

GA treatment significantly reduced the expression of EMT-associated markers and inhibited the migration and invasion of CRC cells

EMT has been shown to endow cancer cells with CSC characteristics [22]. Thus, we reexamined molecular EMT markers in GA-treated CRC cells. As expected, GA-treated CRC cells exhibited the molecular characterization of mesenchyma with a reduced expression of E-cadherin and the enhanced expressions of $\mathrm{N}$-cadherin, vimentin, and fibronectin at the transcriptional level (Fig. 4A). The decreased expression of $\beta$-catenin and vimentin were further verified at the protein level (Fig. 4B). In order to further evaluate whether GA inhibits CRC migration and invasion, we tested the migratory and invasive abilities of GA-treated CRC cells using Transwell migration and Boyden invasion assays. We found that CRC cells treated with GA displayed less migratory and invasive activities than did the control group (Fig. 4C). Our data demonstrate that the decreased migratory and invasive ability of GA-treated CRC cells is coincident with the EMT phenotype. 
Fig. 3. GA treatment decreased stemness-related gene expression in CRC cells. (A) The mRNA levels of ALDH1, Bmi-1, Nanog, Oct4, and CD133 in GA-treated CRC cells and the control group based on qRT-PCR. (B) The protein levels of ALDH1, Bmi-1, Nanog, and Oct4 in GA-treated CRC cells and the control group based on Western blot analysis.

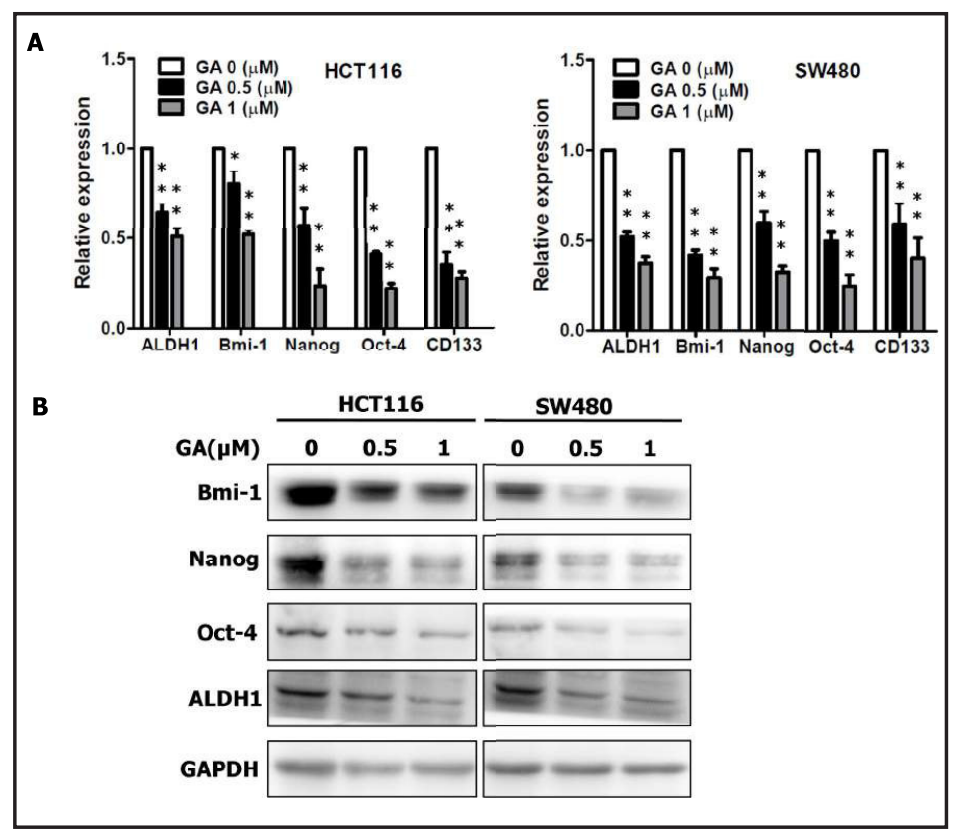

Fig. 4. GA treatment decreased EMT-associated gene expression and the migration and invasion of CRC cells. (A) The mRNA levels of E-cadherin, N-cadherin, Fibronection, and Vimentin in GAtreated CRC cells and the control group based on qRT-PCR. (B) The protein levels of $\beta$-catenin and Vimentin in GA-treated CRC cells and the control group based on Western blot analysis. (C) The motile and invasive capacity of GA-treated CRC cells based on transwell migration and Boyden invasion assays.

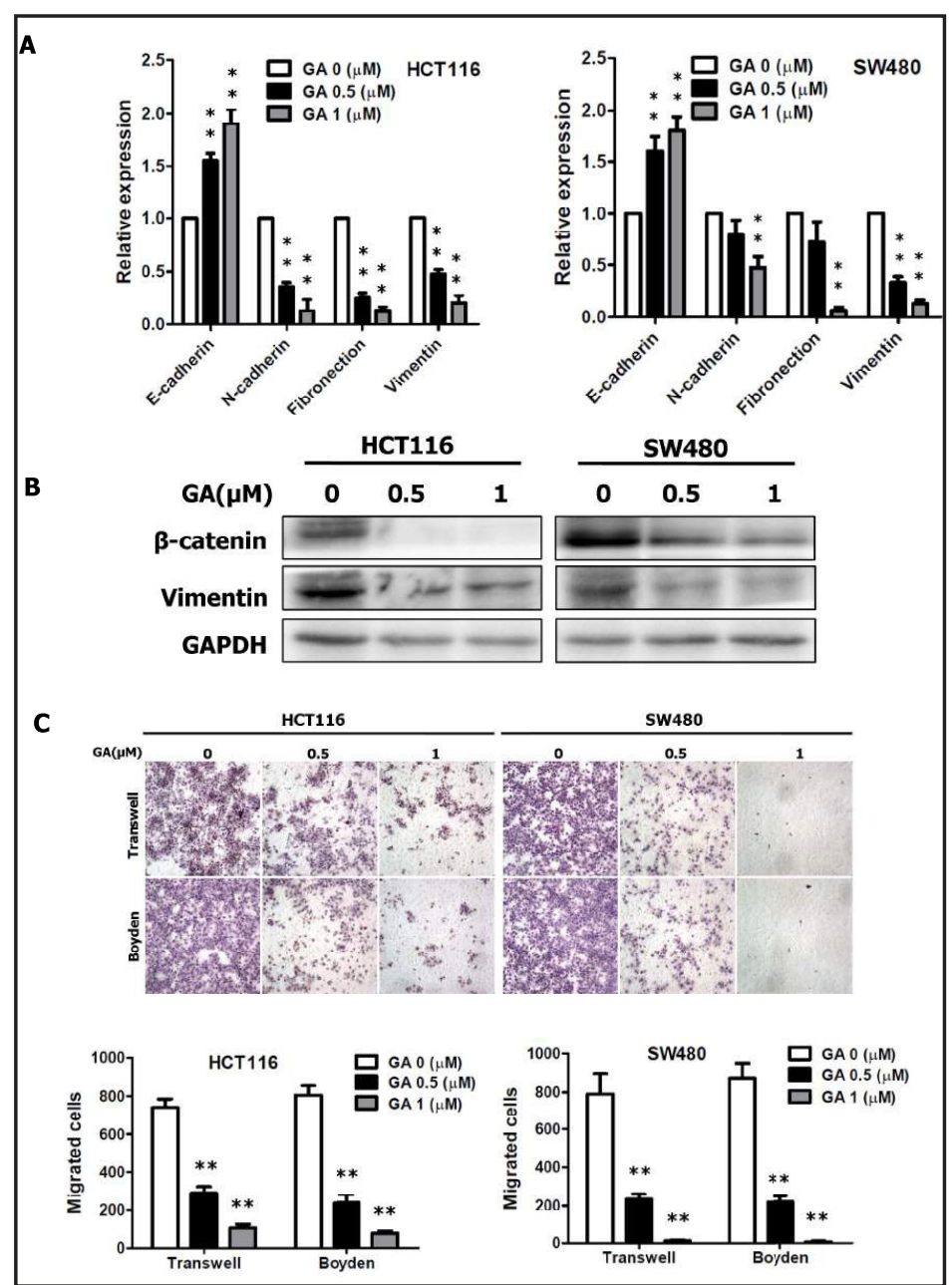


GA killed stem-like CRC cancer cells by upregulating the expression of ZFP36

To identify which downstream genes are affected by GA, an mRNA microarray was performed for SW480 cells before and after GA treatment. After hierarchical clustering (Fig. 5A), the top 50 upregulated ( $>2$-fold) and 37 downregulated (>1.5-fold) genes were correlated with different signaling pathways (Table 1). Notably, GA significantly increased the expression of a panel of genes in the apoptosis signaling pathway, many of which have already been studied by other researchers. Based on gene function and existing research results, we chose ZFP36 as a candidate gene, since it has been associated with tumorigenesis [23], EMT [24], and enhanced cancer invasiveness and metastasis [25]. Furthermore, qRT-PCR verified that partially upregulated and downregulated genes were also affected by GA, whereas ZFP36, as a tumor suppressor gene, increased by 6-8 fold in SW480 cells (Fig. 5B). In addition, western blotting results also showed that ZFP36 was upregulated in CRC cells after GA treatment (Fig. 5C).

In order to ascertain whether GA treatment decreased the stem cell-like population and stemness-related gene expression of CRC cells as mediated by ZFP36, we established stable CRC cells (transfected with shZFP36 or shSCR plasmids) (Fig. 5D-F) and performed lossof-function experiments. We first examined the role of ZFP36 in the maintenance of CRC stemness by ZFP36 knockdown. As shown in Fig. 5, the loss of ZFP36 function through its exogenous expression enhanced the expression of stemness markers (Bmi-1, ALDH1, and ABCG2) (Fig. 5G), and increased the SP cell ratio, the number of colonies, and the number of tumor spheres (Fig. $5 \mathrm{H}$ J). Subsequently, we investigated whether shZFP36 overexpression would rescue the GA treatment-mediated inhibition of stemness gene expression, and reverse the GA-induced drop in the percentages of stem cell-like SP cells, the number of colonies, and the number of tumor spheres in CRC cells. We found that shZFP36 did, indeed, reverse the GA induced downregulation of stemness gene expression (Fig. 5G) and rescued the GA treatmentinduced decline in the percentages of stem cell-like SP cells, colony number, and tumor sphere formation ability in SW480 CRC cells
Table 1. Top 50 upregulated (>2-fold) and 37 downregulated ( $>1.5$-fold) genes after GA treatment in SW480 cells

\begin{tabular}{|c|c|c|c|}
\hline \multicolumn{2}{|c|}{ Upregulated genes } & \multicolumn{2}{|c|}{ Downregulated genes } \\
\hline Fold change & Gene & Fold change & Gene \\
\hline 5.4537 & HSPA1A & 1.5028 & CYTL1 \\
\hline 5.0599 & AKR1C1 & 1.5042 & DPYSL3 \\
\hline 3.4704 & SQSTM1 & 1.5069 & UHRF1 \\
\hline 4.6271 & MAP1B & 1.5072 & TIMELESS \\
\hline 4.6266 & UPP1 & 1.5126 & CA9 \\
\hline 4.5697 & ATF3 & 1.5163 & PHF19 \\
\hline 4.2223 & ZFP36 & 1.5163 & SDPR \\
\hline 4.1853 & DNAJB1 & 1.5242 & THBS1 \\
\hline 3.976 & ZFAND2A & 1.5302 & PTPRE \\
\hline 3.5671 & TRAC & 1.5312 & HIST1H4A \\
\hline 3.3453 & CD55 & 1.5361 & RBM22 \\
\hline 3.3138 & C5orf 45 & 1.5366 & ADAMTS18 \\
\hline 3.0862 & FTH1 & 1.5366 & HMGB3 \\
\hline 2.9918 & CLU & 1.5387 & PAFAH1B3 \\
\hline 2.9401 & BEX2 & 1.5387 & KIAA0101 \\
\hline 2.7456 & DDIT3 & 1.5411 & HPDL \\
\hline 2.7957 & MLLT11 & 1.5480 & HMGB1 \\
\hline 2.7555 & SLC3A2 & 1.5497 & NKD1 \\
\hline 2.7368 & HSPA5 & 1.5516 & ASPSCR1 \\
\hline 2.736 & HERPUD1 & 1.5518 & RPL35A \\
\hline 2.7235 & HMOX1 & 1.5535 & GMFG \\
\hline 2.7052 & LAMB3 & 1.5571 & ILF3 \\
\hline 2.6916 & HSPA6 & 1.5613 & ANTXR1 \\
\hline 2.6497 & AGPAT9 & 1.5676 & SDPR \\
\hline 2.6354 & ANXA1 & 1.5763 & DYPSL2 \\
\hline 2.6297 & TRIB3 & 1.5848 & LSM5 \\
\hline 2.5802 & HKDC1 & 1.6062 & DUT \\
\hline 2.5634 & SPANXB1 & 1.6126 & MYB \\
\hline 2.524 & ASNS & 1.6129 & ASPM \\
\hline 2.3658 & DDIT4 & 1.6186 & RPS14 \\
\hline 2.2697 & SESN2 & 1.6327 & RPL27A \\
\hline 2.2692 & MALAT1 & 1.6359 & FOXQ1 \\
\hline 2.2658 & JUN & 1.6407 & TMSB15A \\
\hline 2.239 & KLF6 & 1.6437 & MYH7B \\
\hline 2.2294 & RAET1L & 1.6966 & PCDH19 \\
\hline 2.2259 & ABCC2 & 1.7274 & TFF3 \\
\hline 2.2066 & RPS2 & 1.8109 & NEK2 \\
\hline 2.2021 & CXCL8 & & \\
\hline 2.1988 & HSPH1 & & \\
\hline 2.1797 & MIR22 & & \\
\hline 2.1682 & BLVRB & & \\
\hline 2.1553 & FTL & & \\
\hline 2.1548 & ADM & & \\
\hline 2.1335 & DUSP1 & & \\
\hline 2.1266 & CEBPB & & \\
\hline 2.0713 & UBC & & \\
\hline 2.0545 & GCLM & & \\
\hline 2.049 & GDF15 & & \\
\hline 2.024 & HSPA8 & & \\
\hline 2.0234 & BAG3 & & \\
\hline
\end{tabular}


Fig. 5. GA killed stem-like cancer cells of CRC by upregulating ZFP36 expression. (A) mRNA microarray analysis revealed differentially expressed mRNA in SW480 cells before and after GA treatment for $24 \mathrm{~h}$. (B) qRTPCR for the mRNA expression of selected candidate genes in the mRNA microarray. (C) The protein levels of ZFP36 in CRC cells treated with GA based on a Western blot assay. (D) Representative GFP expression was measured in CRC cell lines (HCT116 and SW480) transfected with shZFP36 or shSCR recombinant lentiviruses with an inverted fluorescence microscope. (E-F) The mRNA and protein levels of ZFP36 in ZFP36 shRNAor scrambled shRNA-expressing CRC cells based on qRT-PCR and a Western blot assay. (G) The stemness-related protein levels of ZFP36 shRNA-or scrambled shRNA-expressing CRC cells treated with or without GA based on Western blot assay. (H-J) The

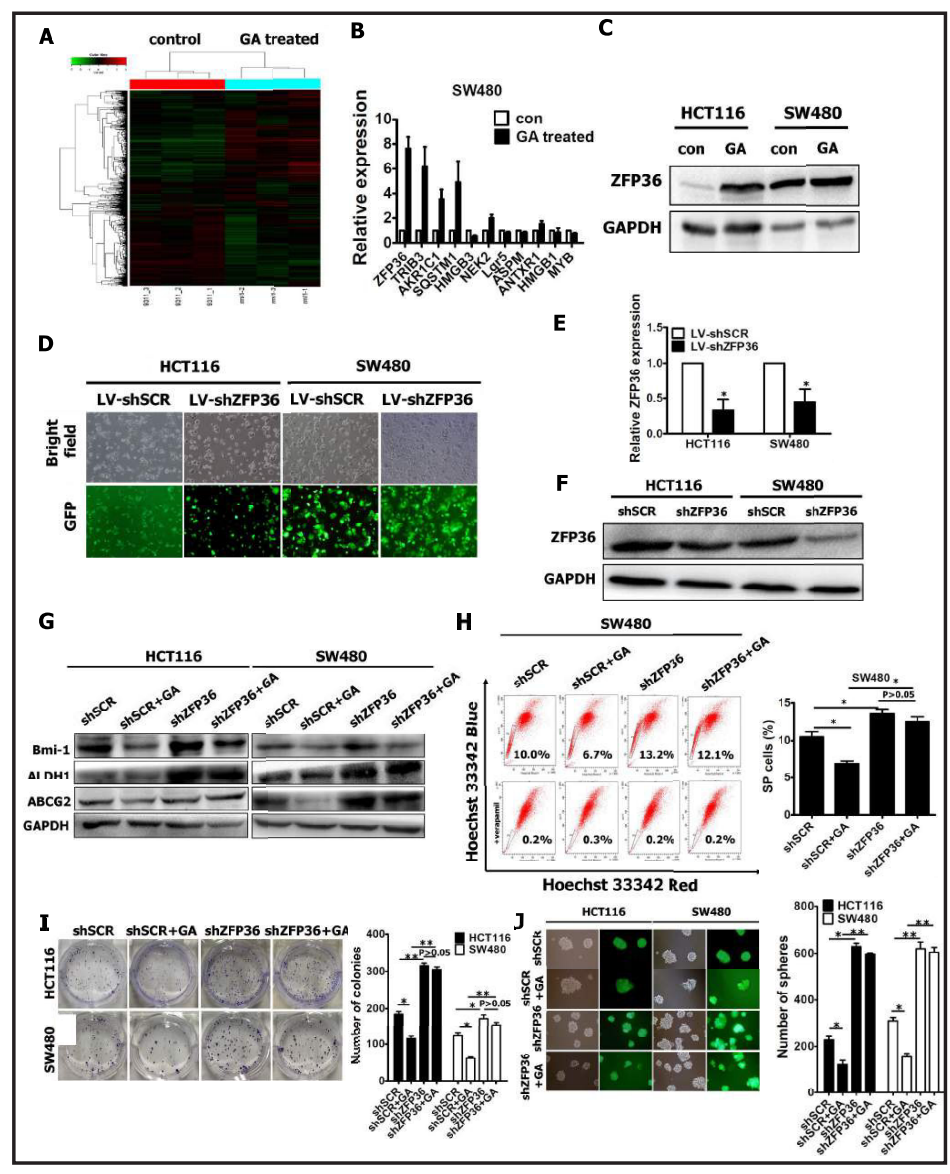
percentages of SP cells $(\mathrm{H})$, colony formation assay (I), and tumor sphere formation assay (J) in ZFP36 shRNA-or scrambled shRNA-expressing CRC cells treated with or without GA.

(Fig. 5H-J). Taken together, these results demonstrate that ZFP36 is involved in the GAinduced decrease in stemness-related gene expression and the stem cell-like population of CRC cells.

\section{GA increased the expression of ZFP36 by inhibiting the EGFR/ERK signaling pathway}

EGFR signaling regulates cell proliferation, differentiation, and tumor cell survival through the activation of EGFR's intrinsic kinases, leading to the subsequent activation of several downstream signaling pathways, including the extracellular related kinase (ERK), phosphoinositide 3-kinase (PI3K), and AKT pathways [26-28]. Furthermore, EGFR signaling is also required for self-renewal of rat embryonic stem cells and cancer stem cells [29-31]. Thus, we performed a western blot analysis to investigate whether GA suppressed the EGFR/ERK signaling pathway in colorectal cancer cells. We observed that GA inhibited the phosphorylation of EGFR and ERK, but that the total levels of EGFR and ERK were unchanged (Fig. 6A), and those of the ZFP36 mRNA and protein were enhanced (Fig. 6A-B). Previous studies have revealed that ZFP36 is a downstream gene of the EGFR/ERK signaling pathway [32]. Subsequently, we investigated the relationship between the EGFR/ERK signaling pathway and ZFP36. When CRC cells were treated with EGFR inhibitor PD153035, we found that the level of ERK phosphorylation was inhibited and ZFP36 protein levels increased (Fig. 6C). Likewise, ZFP36 protein also increased when the ERK inhibitor U0126 was used (Fig. 6D). Taken together, these results indicate that GA could enhance the expression of ZFP36 by inhibiting the EGFR/ERK signaling pathway. 


\section{Cellular Physiology Cell Physiol Biochem 2018;46:829-846 and Biochemistry \begin{tabular}{c|c} 
DOI: 10.1159/000488740 & P 2018 The Author(s). Published by S. Karger AG, Basel \\
www.karger.com/cpb
\end{tabular} Wei et al.: GA Kills Colorectal Cancer Stem Cells}

Fig. 6. GA increased ZFP36 expression through inhibition of the EGFR/ERK signaling pathway. (A) The protein levels of p-EGFR, EGFR, p-ERK, ERK, and ZFP36 in CRC cells treated with GA were detected using western blot analysis. (B) The mRNA level of ZFP36 in CRC cells treated with GA were detected using qRT-PCR. (C) CRC cells were treated with $0.5 \mu \mathrm{M}$ of the EGFR inhibitor PD153035 for 24 $h$. The protein levels of p-EGFR, EGFR, p-ERK, ERK, and ZFP36 were detected using western blot analysis. (D) CRC cells were treated with $10 \mu \mathrm{M}$ of the ERK inhibitor U0126 for $24 \mathrm{~h}$. The protein levels of p-ERK, ERK, and ZFP36 were detected using western blot analysis.

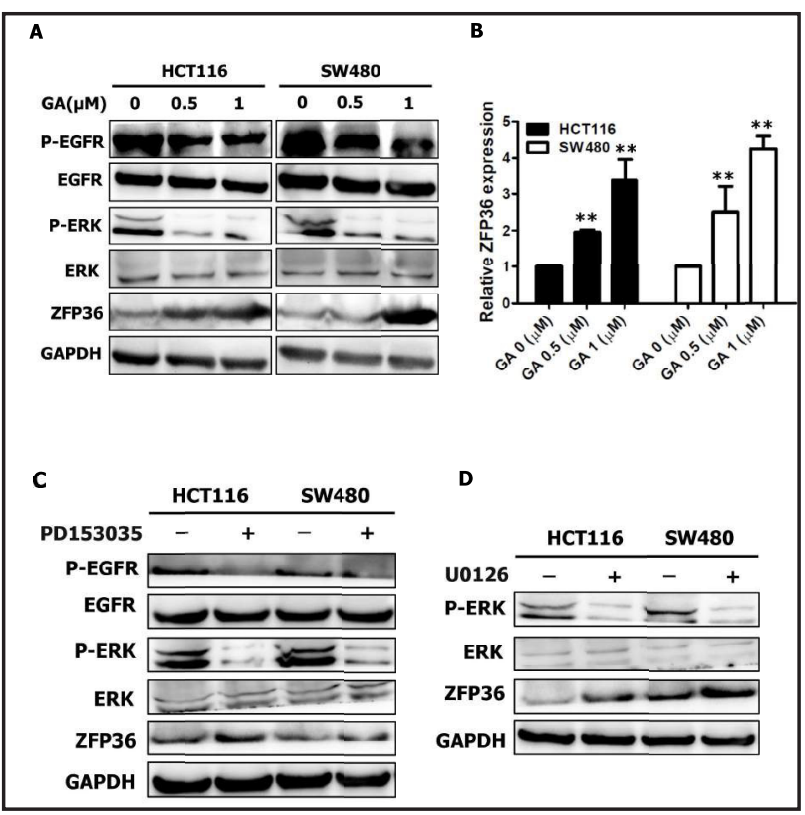

Visualization of putative CSCS of CRC with a "CSC detector"

The development of in vitro methods for optical imaging and non-invasive in vivo detection of putative CSCs is of great importance. Fluorescence and bioluminescence imaging may be the best approach for a given experiment [33-35], both of which have their own merits. Nanog has frequently been used as a CSC-associated marker for the identification of the CSC population from the clinical samples and cell lines of many tumors, including CRC [36-38]. Thus, based on a promoter-reporter gene strategy, we constructed the pLV- $\mathrm{P}_{\text {Nanog }}{ }^{-}$ GFP-T2A-Luc lentivirus vector carrying GFP and Luc reporter genes under the control of the human Nanog promoter (Fig. 7A), which allowed us to visualize CSCs both in vitro and in vivo.

In order to optically visualize CSCs, HCT116 and SW480 cells were infected with the lentivirus harboring $\mathrm{P}_{\text {Nanog }}$-GFP-T2A-Luc (Fig. 7A). Ten days after the infection of CRC cells with LV-P $\mathrm{N}_{\text {Nanog }}$-GFP-T2A-Luc, we found that GFP was highly expressed in a small percentage of stably infected HCT116 and SW480 cells (Fig. 7B). A fluorescence activated cell-sorting analysis showed that $4.0 \%$ of cells were GFP+ in the HCT116 cell line and that $2.1 \%$ were GFP+ in the SW480 cell line (Fig. 7C). Importantly, the Luc signal was strongly correlated with HCT116 cell numbers (Fig. 7D-E) $\left(\mathrm{R}^{2}=0.9922\right)$.

Next, GFP-positive (GFP+) and GFP-negative (GFP-) cells were sorted, and their respective gene expressions were analyzed, while the specific assays mentioned below were performed (Fig. 7F). Fig. 7F shows the significantly increased expression of CSC-related genes (Bmi-1, Oct4, and ABCG2) observed in sorted GFP+ cells, as compared with GFP- cells, indicating that GFP+ cells might have stem-cell-like characteristics. Previous studies have demonstrated that cancer stem cells can form tumor spheres in vitro in a non-attached culture condition. As shown in Fig. 7G, GFP+ cells formed more spheres than GFP- cells. In addition, the colony formation assay indicated that GFP+ cells have greater colony numbers compared to GFPcells (Fig. 7H). GFP+ cancer cells exhibit the characteristics of CSCs.

To examine whether GFP+ cells are efficiently migratory and highly invasive, we used Transwell migration and matrigel-coated Boyden chamber assays, respectively. Our data revealed that GFP+ cells illustrated a dramatic increase in motile capacity and invasive ability compared with GFP- cells (Fig. 7I). The epithelial-mesenchymal transition (EMT) has been shown to endow cancer cells with a strong invasive ability. Thus, we next used qRT-PCR to test for EMT-related markers in both GFP+ and GFP- cells. As expected, GFP+ cells exhibited the molecular characterization of mesenchyma with reduced E-cadherin expression and 


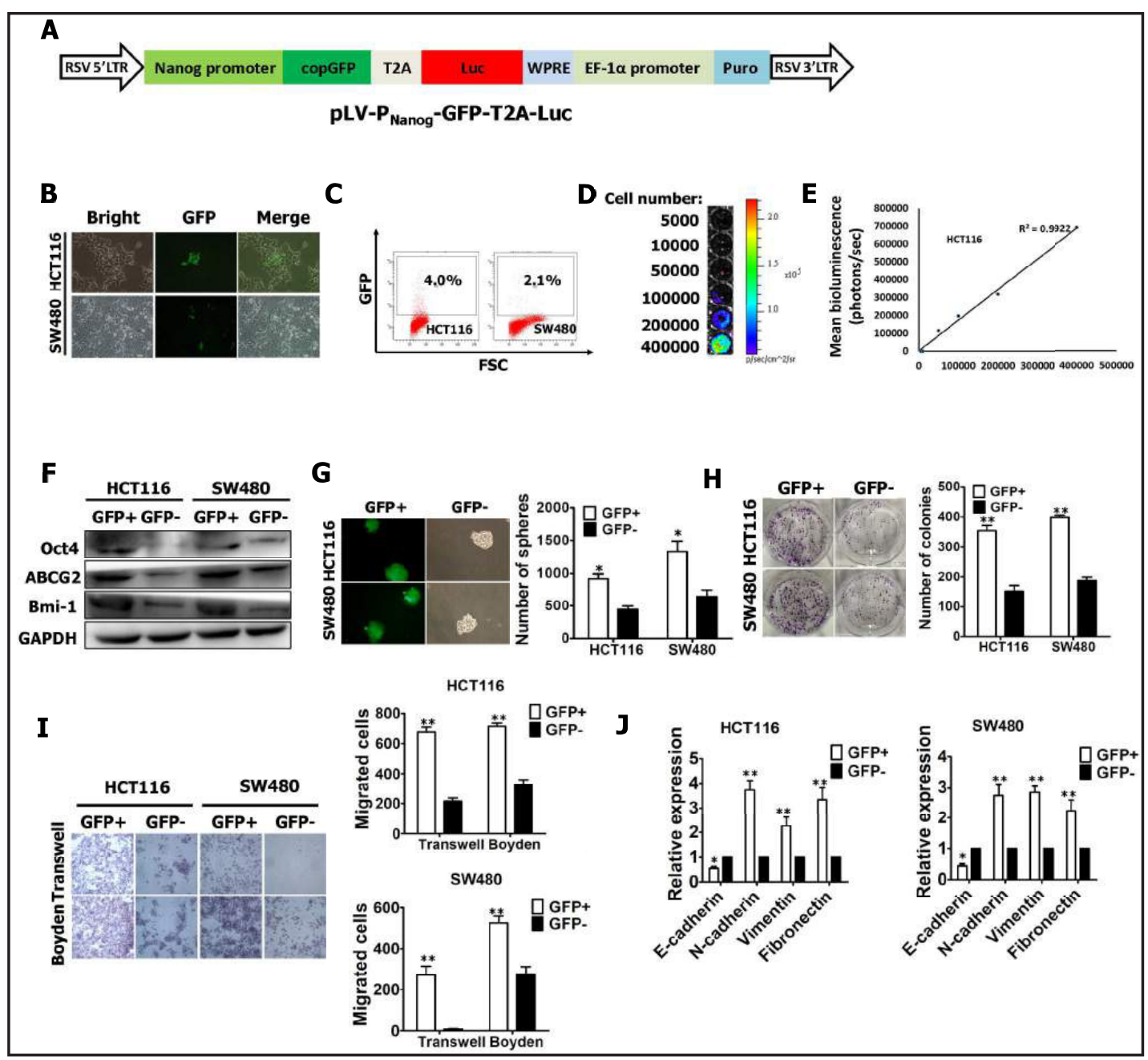

Fig. 7. Visualization of putative CSCs of CRC with a "CSC detector". (A) Schematic diagram of lentiviral vector pLV-P ${ }_{\text {Nanog }}$-GFP-T2A-Luc, in which GFP (green fluorescent protein) and Luc (firefly luciferase) expressions were controlled by the human Nanog promoter. (B-C) Representative GFP expression was measured in CRC cell lines (HCT116 and SW480) harboring $\mathrm{P}_{\text {Nanog }}$-GFP-T2A-Luc transgene by inverted fluorescence microscope (B) and by flow cytometry (C). (D) HCT116 cells carrying Luc have robust reporter gene expression as shown by bioluminescence imaging (BLI). (E) A strong correlation exists between the BLI signal and HCT116 cell number. (F-G) GFP+ and GFP- fractions sorted from HCT116 and SW480 cells carrying $\mathrm{P}_{\text {Nanog }}{ }^{-}$ GFP-T2A-Luc transgene by fluorescence-activated cell sorting (FACS) were subjected to Western blotting for the detection of Bmi-1, Oct4, and ABCG2 expression (F), and tumor sphere formation assay (G). (H-I) The growth (H), migration, and invasion (I) of GFP+ and GFP-CRC cells were evaluated by colony formation assay, Transwell, and Boyden assays, respectively. GFP+ and GFP- fractions were sorted from HCT116 and SW480 cells carrying the $\mathrm{P}_{\text {Nano }}$-GFP-T2A-Luc transgene, via FACS.. (J) GFP+ and GFP- fractions sorted from HCT116 and SW480 cells carrying $\mathrm{P}_{\text {Nanog }}$-GFP-T2A-Luc transgene via FACS were subjected to qRT-PCR for the detection of E-cadherin, N-cadherin, Vimentin, and Fibronectin expression.

increased N-cadherin, Vimentin, and Fibronectin expression (Fig. 7J), demonstrating that the increased migratory and invasive capacity of GFP+ cancer cells is coincident with the EMT phenotype.

Our data explored the ways in which GFP+ cells harboring the $\mathrm{P}_{\text {Nanog }}$-GFP-T2A-Luc transgene exhibited the characteristics of CSCs. Therefore, the newly established CRC cell line harboring the $\mathrm{P}_{\text {Nanog }}$-GFP-T2A-Luc transgene allows for the better visualization and monitoring of a small population of putative CSCs both in vitro and in vivo.

\section{KARGER}


Fig. 8. In vivo bioluminescence imaging of GA killing activity against putative CSCs of CRC. (A) Series of in vivo bioluminescence images (taken at the indicated times) of 2 representative nude mice from the GA and control groups before and after GA treatment. (B) Growth curve of tumor volumes. (C) Quantification analysis of bioluminescence signal of tumor-bearing mice treated with GA or control group. (D) Representative picture of tumors. (E) Tumors were weighed. (F) Ki67, Nanog, p-EGFR, p-ERK, and ZFP36-stained sections of transplanted tumors formed by HCT 116 cells 20 days after subcutaneous transplantation. The percentages of Ki67-, Nanog-, p-EGFR-, p-ERK-, or ZFP36-positive cancer cells were calculated by the total number of Ki67-, Nanog-, p-EGFR-, p-ERK-, or ZFP36positive cells over total

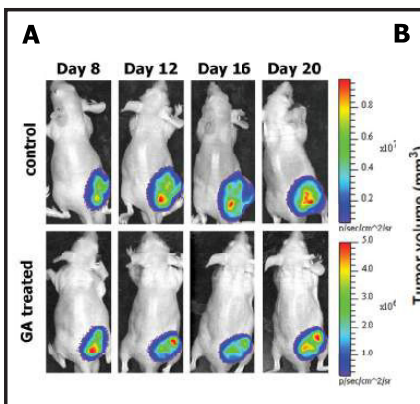

D

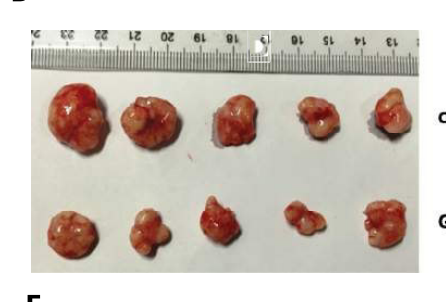

B C
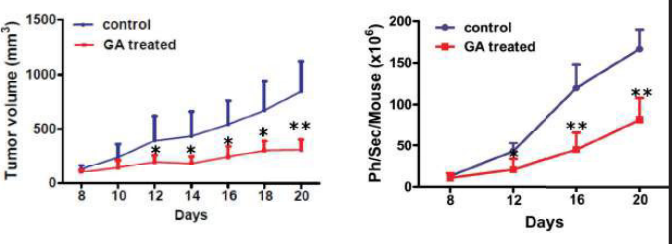

E

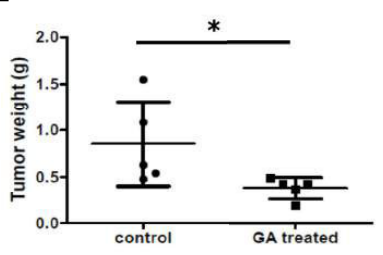

$\mathbf{F}$
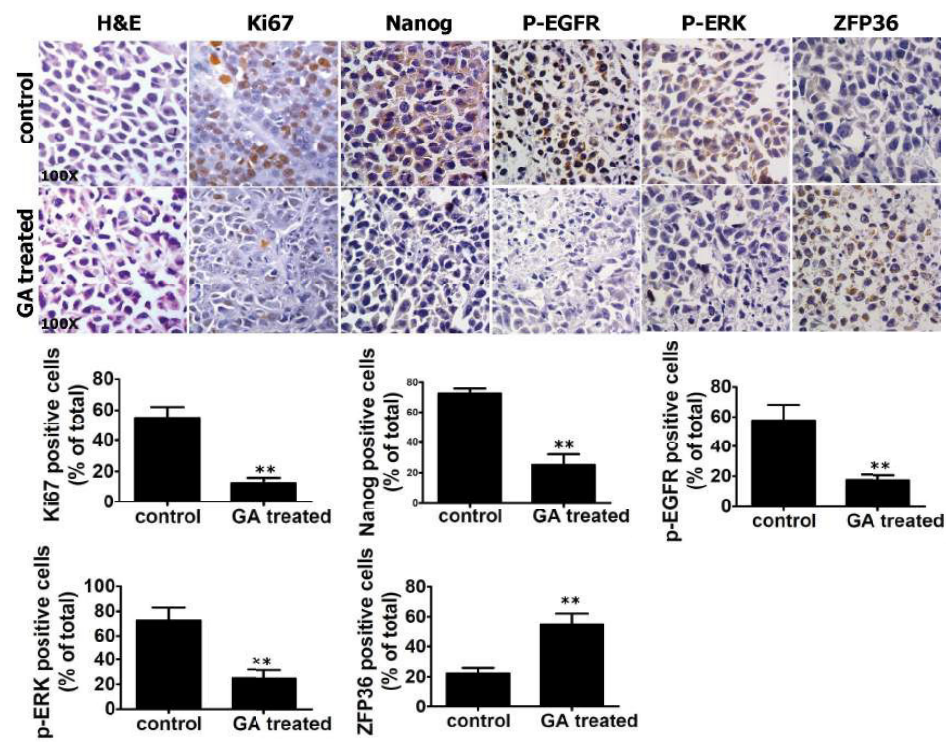
number of cancer cells.

In vivo bioluminescence imaging of GA killing activity against putative CSCS of CRC

As shown by various efficient in vitro methods, GA exhibited a strong ability to kill putative CSCs of CRC. We next evaluated the antitumor activity of GA against putative CSCs of CRC in nude mice by in vivo optical imaging. As mentioned above, the established HCT116 cells carrying GFP and the Luc reporter gene under the control of the Nanog promoter allowed us to monitor a rare population of putative CSCs in human tumor xenograft-bearing mice using in vivo bioluminescence imaging.

First, nude mice were subcutaneously implanted with HCT116 cells $\left(1 \times 10^{6}\right)$ harboring the $\mathrm{P}_{\text {Nanog }}$-GFP-T2A-Luc transgene. Starting one week after HCT116 cell implantation, GA $(1 \mathrm{mg} / \mathrm{kg})$ was intraperitoneally injected into the mice each day. A significant reduction in tumor growth was observed in the GA-treated mice compared with the controls (Fig. 8A, B) As early as 4 days after GA treatment, the growth of the transplanted tumors between GA-treated mice and controls became statistically significant $(P<0.05$ or 0.01 , Fig.8B), respectively. On day 20 , all tumors were excised and weighed, in order to further illustrate the strong anti-tumor activity of GA against HCT116 cells (Fig. 8D, E). The results of the ensuing 


\section{Cellular Physiology Cell Physiol Biochem 2018;46:829-846 \begin{tabular}{l|l} 
DOI: 10.1159/000488740 & O 2018 The Author(s). Published by S. Karger AG, Basel \\
www.karger.com/cpb
\end{tabular} \\ Wei et al.: GA Kills Colorectal Cancer Stem Cells}

immunohistochemical analysis revealed that the number of hyperproliferative Ki67-positive tumor cells in the GA-treated group decreased significantly (Fig. 8F).

The above-mentioned data from these conventional methods exhibited a significant delay in the growth of subcutaneous tumor xenografts observed in GA-treated mice (Fig. 8B, D, E, F). The established subcutaneous tumor xenografts, expressing both GFP and the Luc reporter gene under the control of the Nanog promoter, allowed us to detect putative CSCs in human tumor xenograft-bearing mice using bioluminescence imaging. Therefore, after the sizes of the subcutaneous tumors were determined by caliper measurement, tumor bearing mice were imaged at days $8,12,16$, and 20 by in vivo bioluminescence imaging to detect the changes in the number of putative CSCs. As shown in Fig. 8A, C, after GA treatment, a significant bioluminescence signal reduction was found in GA-treated mice compared with untreated controls and, as early as 12 days post-treatment, the signal intensities between GA treated mice and the controls became statistically significant $(P<0.05$ or 0.01$)$. We further detected the percentage of Nanog-positive cells using a Nanog antibody-based staining method. As shown in Fig. 8F, significant decreases in the percentage of Nanog-positive cells were found in GA treated mice compared with controls, suggesting a general downward trend in the number of putative CSCs within the tumor xenografts. These findings from both in vivo bioluminescence imaging and Nanog antibody-based staining clearly demonstrate that GA treatment leads to the remarkable reduction in the number of putative CSCs within tumor xenografts, demonstrating that GA can efficiently kill putative CSCs in vivo.

To determine the mechanism by which GA killed putative CSCs of CRC through the inhibition of the EGFR/ERK/ZFP36 pathway in vivo, an IHC analysis was performed in the tumor tissues of the two experimental groups. The expression of p-EGFR, p-ERK was significantly reduced in the GA group, while ZFP36 was significantly enhanced compared with the control (Fig. 8F), in support of the in vitro results.

\section{Discussion}

Recent studies have demonstrated the preclinical antitumor activity of GA against multiple types of tumors, including colorectal cancer $[39,40]$. However, whether or not it inhibits the growth of tumoral CSCs has not yet been elucidated. Intensive research should be done to explore the inhibitory activity of GA against CSCs of various cancers, since CSCs are associated with tumor therapy failure. Our study showed the intense tumor killing activity of GA against CSCs of CRC both in vitro (tumor sphere formation assay, detection of SP and $\mathrm{CD} 133^{+} \mathrm{CD} 44^{+}$cells, antitumor activity of GA against CD $133^{+} \mathrm{CD} 44^{+} \mathrm{CSCs}$, and detection of stem cells markers) and in vivo (optical imaging and quantifying putative CSCs within tumor bearing mice using in vivo bioluminescence imaging).

We further explored the mechanisms underlying the antitumor effects of GA on CSCs of CRC. We identified ZFP36 as a potential downstream gene affected by GA using an mRNA microarray. ZFP36 was originally described as an active regulator of the inflammatory response, but recent reports show that its expression is commonly deficient in a number of cancer cell types when compared to normal cells [41]. Moreover, ZFP36 expression seems to counteract the progression of malignancy [42, 43]. In this study, our results showed that ZFP36 was upregulated in CRC cells after GA treatment and was involved in the maintenance of CRC cell stemness through the suppression of ZFP36 expression by shRNA.

Next, we explored whether or not the GA treatment decrease in the stem cell-like population and stemness-related gene expression of CRC cells was mediated by ZFP36. ZFP36 has been reported to be involved in the regulation of proliferation and EMT of many tumors via different signaling pathways $[24,44,45]$. There are no publications, however, on whether ZFP36 regulates the stemness of colorectal cancer stem cells. In the present study, we first examined the role of ZFP36 in the maintenance of CRC cell stemness through the exogenous shZFP36 expression using various methods (tumor sphere formation assay, detection of SP cell percentage, and detection of stem cells markers). In addition, we found 
that shZFP36 reversed the GA-induced downregulation of stemness gene expression and rescued the GA-induced reduction in colony and tumor sphere formation and the percentages of stem cell-like SP cells in CRC. GA treatment decreased the stem cell-like population and stemness related gene expression of CRC cells by upregulating ZFP36. Previous studies have revealed that ZFP36 is a downstream gene in the EGFR and ERK signaling pathway [32], which is also required for the self-renewal of cancer stem cells in addition to regulating proliferation and survival [31]. KEGG pathway analyses and related studies have reported that GA can downregulate the EGFR and ERK signaling pathway [46]. Furthermore, our results revealed that GA could increase the expression of ZFP36 by inhibiting the EGFR/ERK signaling pathway. As a traditional Chinese medicine extract, we showed that GA exerted a multi-target inhibitory effect, and might have the potential for further therapeutic use in colorectal cancer.

Increasing evidence has revealed that CSCs are responsible for tumorigenicity, progression, therapeutic resistance, and tumor recurrence. Thus, the development of methods for in vitro optical imaging and the non-invasive in vivo detection of putative CSCs is of great importance [34, 35]. In our previous nasopharyngeal carcinoma and liver cancer studies $[47,48]$, we developed a new methodology for both the in vitro and in vivo visualization of putative CSCs based on a lentiviral "CSC detector" vector encoding the GFP and Luc proteins controlled by the human Nanog promoter, which has never previously been reported. In this study, in order to visualize the CSCs of CRC cells, HCT116 and SW480 cells were infected with the lentiviruses carrying $\mathrm{P}_{\text {Nanog }}$-GFP-T2A-Luc. We then sorted GFP+ cancer cells (putative CSCs) from CRC cells carrying the $\mathrm{P}_{\text {Nanoo }}$-GFP-T2A-Luc transgene and exhibiting the characteristics of CSCs. Based on these results, the noninvasive in vivo bioluminescence imaging, via the detection of Luc expression, allowed us to monitor the remarkable reduction in the number of putative CSCs within tumor bearing mice after GA treatment. Therefore, the newly established CRC cell line harboring GFP and Luc reporter genes under the control of the Nanog promoter allowed us to visualize putative CSCs within tumor xenograft-bearing mice, which has never been reported in colorectal cancer.

CSCs are the root cause for cancer treatment failure. Nevertheless, the development of new therapeutic strategies targeting CSCs is currently hindered by the lack of special markers for their identification. Moreover, one of the key goals in cancer research over the past decade has been to develop therapeutic strategies to eliminate CSCs and to cure the cancer with little to no damage to normal tissues, but a major barrier to this goal lies in the identification of the key mechanisms that distinguish CSCs from normal endogenous tissue stem cells.

Gambogic acid (GA) is expected to be a potential new antitumor drug, but its poor aqueous solubility and accompanying toxic side effects limit its bioavailability in clinical applications $[49,50]$. Fortunately, several strategies have been adopted to improve the anti-tumor efficacy of both soluble and insoluble drugs. These strategies include the use of tumor cell-derived microparticles (T-MPs) and biomimetic nanoparticle-based therapies to improve the antitumor efficacy of drugs with relatively low toxicity [51,52]. Drug-packaging MPs have shown promising anti-tumor activity [51]. They possess multiple advantages in cancer therapy, including their (i) efficient packaging of both soluble and insoluble drugs; (ii) ability to package large amounts of drug molecules; and (iii) safety and nontoxicity. In addition, the preparation of tumor cell-derived, drug-packaging MPs is simple, further facilitating their applicability. These features make drug-packaging MPs highly efficacious in targeting tumor cells, especially for cancer stem cells [51].

RBCm (red blood-cell membrane)-GA/PLGA (poly lactic-co-glycolic acid) NPs (nanoparticles) has been used as a biomimetic nanocarrier and united the customizability and flexibility of synthetic copolymer PLGA with the functionality and complexity of natural liposome RBCm [52]. The loading of the potential antitumor drug GA bestowed a new antitumor efficacy on the nanocarrier. The combination of $\mathrm{RBCm}$ and PLGA has been shown to enhance the stability and biocompatibility of a composite carrier compared with bare nanoerythrosomes and a polymeric carrier [52]. Previous research has demonstrated

\section{KARGER}




\section{Cellular Physiology Cell Physiol Biochem 2018;46:829-846

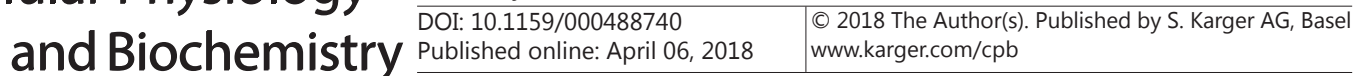 \\ Wei et al.: GA Kills Colorectal Cancer Stem Cells}

that the synthetic RBC-NP platform enhances the anti-tumoral efficiency of GA [52]. It is necessary, therefore, to explore whether or not GA-loaded RBC NPs kill stem-like cancer cells of colorectal cancer more efficiently than does GA alone.

\section{Conclusion}

In conclusion, our in vitro and in vivo findings here demonstrate the intense tumor killing activity of GA against putative CSCs of CRC through the inactivation of the EGFR/ERK/ZFP36 signaling pathway. Further research is required to identify the role of the EGFR/ERK/ZFP36 signaling pathway in the therapeutic use of GA and the maintenance of the stemness of CRC cells. We will carry out further preclinical and clinical investigations on the prospective potential of targeting putative CSCs of CRC with GA-packaging MPs and GA-loaded RBC NPs.

\section{Acknowledgements}

This work was supported by the National Natural Science Foundation of China (Grant No. 81602598, to F. Wei), the Science and Technology Planning Project of Guangdong Province of China (Grant No. 2017A020215009, to F. Wei), and the Fundamental Research Funds for the Central Universities (Grant No. 2017MS125, to F. Wei), Guangzhou Science Technology and Innovation Commission (2014Y2-00137, to J. Cao).

All experiments of this study were authorized by the Ethics Committee of Guangzhou First People's Hospital (K2016-103-01).

\section{Disclosure Statement}

The authors declare that they have no competing interests.

\section{References}

1 Tenbaum SP, Ordonez-Moran P, Puig I, Chicote I, Arques O, Landolfi S, Fernandez Y, Herance JR, Gispert JD, Mendizabal L, Aguilar S, Ramony- Cajal S, Schwartz S, Vivancos A, Espin E, Rojas S, Baselga J, Tabernero

J, Munoz A, Palmer HG: Beta-catenin confers resistance to pi3k and akt inhibitors and subverts foxo3a to promote metastasis in colon cancer. Nat Med 2012;18:892-901.

-2 Ordonez-Moran P, Dafflon C, Imajo M, Nishida E, Huelsken J: Hoxa5 counteracts stem cell traits by inhibiting wnt signaling in colorectal cancer. Cancer Cell 2015;28:815-829.

-3 Guinney J, Dienstmann R, Wang X, de Reynies A, Schlicker A, Soneson C, Marisa L, Roepman P, Nyamundanda G, Angelino P, Bot BM, Morris JS, Simon IM, Gerster S, Fessler E, De Sousa EMF, Missiaglia E, Ramay H, Barras D, Homicsko K, Maru D, Manyam GC, Broom B, Boige V, Perez-Villamil B, Laderas T, Salazar R, Gray JW, Hanahan D, Tabernero J, Bernards R, Friend SH, Laurent-Puig P, Medema JP, Sadanandam A, Wessels L, Delorenzi M, Kopetz S, Vermeulen L, Tejpar S: The consensus molecular subtypes of colorectal cancer. Nat Med 2015;21:1350-1356.

4 Guo QL, Lin SS, You QD, Gu HY, Yu J, Zhao L, Qi Q Liang F, Tan Z, Wang X: Inhibition of human telomerase reverse transcriptase gene expression by gambogic acid in human hepatoma smmc-7721 cells. Life Sci 2006;78:1238-1245.

5 Zhao L, Guo QL, You QD, Wu ZQ, Gu HY: Gambogic acid induces apoptosis and regulates expressions of bax and bcl-2 protein in human gastric carcinoma mgc-803 cells. Biol Pharm Bull 2004;27:998-1003.

6 Wu ZQ Guo QL, You QD, Zhao L, Gu HY: Gambogic acid inhibits proliferation of human lung carcinoma spc-a1 cells in vivo and in vitro and represses telomerase activity and telomerase reverse transcriptase mrna expression in the cells. Biol Pharm Bull 2004;27:1769-1774.

7 Pandey MK, Sung B, Ahn KS, Kunnumakkara AB, Chaturvedi MM, Aggarwal BB: Gambogic acid, a novel ligand for transferrin receptor, potentiates tnf-induced apoptosis through modulation of the nuclear factorkappab signaling pathway. Blood 2007;110:3517-3525. 


\section{Cellular Physiology Cell Physiol Biochem 2018;46:829-846

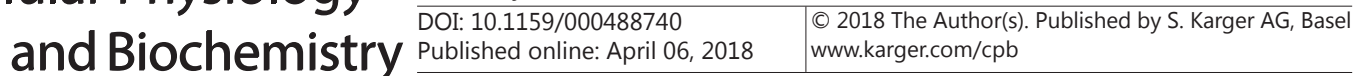 \\ Wei et al.: GA Kills Colorectal Cancer Stem Cells}

8 Yu J, Guo QL, You QD, Zhao L, Gu HY, Yang Y, Zhang HW, Tan Z, Wang X: Gambogic acid-induced g2/m phase cell-cycle arrest via disturbing cdk7-mediated phosphorylation of cdc2/p34 in human gastric carcinoma bgc-823 cells. Carcinogenesis 2007;28:632-638.

-9 Zhao Q, Yang Y, Yu J, You QD, Zeng S, Gu HY, Lu N, Qi Q, Liu W, Wang XT, Guo QL: Posttranscriptional regulation of the telomerase htert by gambogic acid in human gastric carcinoma 823 cells. Cancer Lett 2008;262:223-231.

-10 Yi T, Yi Z, Cho SG, Luo J, Pandey MK, Aggarwal BB, Liu M: Gambogic acid inhibits angiogenesis and prostate tumor growth by suppressing vascular endothelial growth factor receptor 2 signaling. Cancer Res 2008;68:1843-1850.

11 Qi Q, Lu N, Wang XT, Gu HY, Yang Y, Liu W, Li C, You QD, Guo QL: Anti-invasive effect of gambogic acid in mda-mb-231 human breast carcinoma cells. Biochem Cell Biol 2008;86:386-395.

12 Jackson M, Hassiotou F, Nowak A: Glioblastoma stem-like cells: At the root of tumor recurrence and a therapeutic target. Carcinogenesis 2015;36:177-185.

13 Matchett KB, Lappin TR: Concise reviews: Cancer stem cells: From concept to cure. Stem Cells 2014;32:2563-2570.

14 Vidal SJ, Rodriguez-Bravo V, Galsky M, Cordon-Cardo C, Domingo-Domenech J: Targeting cancer stem cells to suppress acquired chemotherapy resistance. Oncogene 2014;33:4451-4463.

15 Wang SC, Lin XL, Li J, Zhang TT, Wang HY, Shi JW, Yang S, Zhao WT, Xie RY, Wei F, Qin YJ, Chen L, Yang J, Yao KT, Xiao D: Microrna-122 triggers mesenchymal-epithelial transition and suppresses hepatocellular carcinoma cell motility and invasion by targeting rhoa. PloS One 2014;9:e101330.

16 Shi JW, Liu W, Zhang TT, Wang SC, Lin XL, Li J, Jia JS, Sheng HF, Yao ZF, Zhao WT, Zhao ZL, Xie RY, Yang S, Gao F, Fan QR, Zhang MY, Yue M, Yuan J, Gu WW, Yao KT, Xiao D: The enforced expression of c-myc in pig fibroblasts triggers mesenchymal-epithelial transition (met) via f-actin reorganization and rhoa/rock pathway inactivation. Cell Cycle 2013;12:1119-1127.

17 Du T, Jia J, Lin X, Xie R, Li J, Xiao D, Xu K: Generation of rm21lg transgenic mice: A powerful tool to generate conditional overexpression of mir-21 that is involved in oncogenesis. Biotechnol lett 2014;36:9-20.

18 Liu Y, Clem B, Zuba-Surma EK, El-Naggar S, Telang S, Jenson AB, Wang Y, Shao H, Ratajczak MZ, Chesney J, Dean DC: Mouse fibroblasts lacking rb1 function form spheres and undergo reprogramming to a cancer stem cell phenotype. Cell Stem Cell 2009;4:336-347.

19 Kong QL, Hu LJ, Cao JY, Huang YJ, Xu LH, Liang Y, Xiong D, Guan S, Guo BH, Mai HQ Chen QY, Zhang X, Li MZ, Shao JY, Qian CN, Xia YF, Song LB, Zeng YX, Zeng MS: Epstein-barr virus-encoded lmp2a induces an epithelial-mesenchymal transition and increases the number of side population stem-like cancer cells in nasopharyngeal carcinoma. PLoS Pathog 2010;6:e1000940.

20 Ricci-Vitiani L, Lombardi DG, Pilozzi E, Biffoni M, Todaro M, Peschle C, De Maria R: Identification and expansion of human colon-cancer-initiating cells. Nature 2007;445:111-115.

-21 Stotz M, Herzog SA, Pichler M, Smolle M, Riedl J, Rossmann C, Bezan A, Stoger H, Renner W, Berghold A, Gerger A: Cancer stem cell gene variants in cd44 predict outcome in stage ii and stage iii colon cancer patients. Anticancer Res 2017;37:2011-2018.

-22 Mani SA, Guo W, Liao MJ, Eaton EN, Ayyanan A, Zhou AY, Brooks M, Reinhard F, Zhang CC, Shipitsin M, Campbell LL, Polyak K, Brisken C, Yang J, Weinberg RA: The epithelial-mesenchymal transition generates cells with properties of stem cells. Cell 2008;133:704-715.

23 Rounbehler RJ, Fallahi M, Yang C, Steeves MA, Li W, Doherty JR, Schaub FX, Sanduja S, Dixon DA, Blackshear PJ, Cleveland JL: Tristetraprolin impairs myc-induced lymphoma and abolishes the malignant state. Cell 2012;150:563-574.

24 Montorsi L, Guizzetti F, Alecci C, Caporali A, Martello A, Atene CG, Parenti S, Pizzini S, Zanovello P, Bortoluzzi S, Ferrari S, Grande A, Zanocco-Marani T: Loss of zfp36 expression in colorectal cancer correlates to wnt/ ss-catenin activity and enhances epithelial-to-mesenchymal transition through upregulation of zeb1, sox9 and macc1. Oncotarget 2016;7:59144-59157.

25 Van Tubergen EA, Banerjee R, Liu M, Vander Broek R, Light E, Kuo S, Feinberg SE, Willis AL, Wolf G, Carey T, Bradford C, Prince M, Worden FP, Kirkwood KL, D'Silva NJ: Inactivation or loss of ttp promotes invasion in head and neck cancer via transcript stabilization and secretion of mmp9, mmp2, and il-6. Clin Cancer Res 2013;19:1169-1179.

-26 Normanno N, De Luca A, Bianco C, Strizzi L, Mancino M, Maiello MR, Carotenuto A, De Feo G, Caponigro F, Salomon DS: Epidermal growth factor receptor (egfr) signaling in cancer. Gene 2006;366:2-16. 


\section{Cellular Physiology Cell Physiol Biochem 2018;46:829-846 \begin{tabular}{l|l} 
DOI: 10.1159/000488740 & $\begin{array}{l}\text { O 2018 The Author(s). Published by S. Karger AG, Basel } \\
\text { www.karger.com/cpb }\end{array}$ \\
\hline
\end{tabular} \\ Wei et al.: GA Kills Colorectal Cancer Stem Cells}

27 Mangelberger D, Kern D, Loipetzberger A, Eberl M, Aberger F: Cooperative hedgehog-egfr signaling. Front Biosci 2012;17:90-99.

28 Eccles SA: The epidermal growth factor receptor/erb-b/her family in normal and malignant breast biology. Int J Dev Biol 2011;55:685-696.

29 Maric D, Maric I, Chang YH, Barker JL: Prospective cell sorting of embryonic rat neural stem cells and neuronal and glial progenitors reveals selective effects of basic fibroblast growth factor and epidermal growth factor on self-renewal and differentiation. J Neurosci 2003;23:240-251.

-30 Chen JS, Pardo FS, Wang-Rodriguez J, Chu TS, Lopez JP, Aguilera J, Altuna X, Weisman RA, Ongkeko WM: Egfr regulates the side population in head and neck squamous cell carcinoma. Laryngoscope 2006;116:401-406.

-31 Feng Y, Dai X, Li X, Wang H, Liu J, Zhang J, Du Y, Xia L: Egf signalling pathway regulates colon cancer stem cell proliferation and apoptosis. Cell Prolif 2012;45:413-419.

-32 Bourcier C, Griseri P, Grepin R, Bertolotto C, Mazure N, Pages G: Constitutive erk activity induces downregulation of tristetraprolin, a major protein controlling interleukin8/cxcl8 mrna stability in melanoma cells. Am J Physiol Cell Physiol 2011;301:C609-618.

-33 Sun N, Lee A, Wu JC: Long term non-invasive imaging of embryonic stem cells using reporter genes. Nat Protoc 2009;4:1192-1201.

34 Heryanto YD, Achmad A, Taketomi-Takahashi A, Tsushima Y: In vivo molecular imaging of cancer stem cells. Am J Nucl Med Mol Imaging 2015;5:14-26.

-35 Hart LS, El-Deiry WS: Invincible, but not invisible: Imaging approaches toward in vivo detection of cancer stem cells. J Clin Oncol 2008;26:2901-2910.

-36 Wahab SMR, Islam F, Gopalan V, Lam AK: The identifications and clinical implications of cancer stem cells in colorectal cancer. Clin Colorectal Cancer 2017;16:93-102.

-37 Lu LL, Chen XH, Zhang G, Liu ZC, Wu N, Wang H, Qi YF, Wang HS, Cai SH, Du J: Ccl21 facilitates chemoresistance and cancer stem cell-like properties of colorectal cancer cells through akt/gsk-3beta/ snail signals. Oxid Med Cell Longev 2016;2016:5874127.

38 Yao C, Su L, Shan J, Zhu C, Liu L, Liu C, Xu Y, Yang Z, Bian X, Shao J, Li J, Lai M, Shen J, Qian C: Igf/stat3/ nanog/slug signaling axis simultaneously controls epithelial-mesenchymal transition and stemness maintenance in colorectal cancer. Stem Cells 2016;34:820-831.

-39 Shi X, Chen X, Li X, Lan X, Zhao C, Liu S, Huang H, Liu N, Liao S, Song W, Zhou P, Wang S, Xu L, Wang X, Dou QP, Liu J: Gambogic acid induces apoptosis in imatinib-resistant chronic myeloid leukemia cells via inducing proteasome inhibition and caspase-dependent bcr-abl downregulation. Clin Cancer Res 2014;20:151-163.

-40 Wen C, Huang L, Chen J, Lin M, Li W, Lu B, Rutnam ZJ, Iwamoto A, Wang Z, Yang X, Liu H: Gambogic acid inhibits growth, induces apoptosis, and overcomes drug resistance in human colorectal cancer cells. Int J Oncol 2015;47:1663-1671.

-41 Brennan SE, Kuwano Y, Alkharouf N, Blackshear PJ, Gorospe M, Wilson GM: The mrna-destabilizing protein tristetraprolin is suppressed in many cancers, altering tumorigenic phenotypes and patient prognosis. Cancer Res 2009;69:5168-5176.

-42 Baou M, Jewell A, Muthurania A, Wickremasinghe RG, Yong KL, Carr R, Marsh P, Murphy JJ: Involvement of tis11b, an au-rich binding protein, in induction of apoptosis by rituximab in b cell chronic lymphocytic leukemia cells. Leukemia 2009;23:986-989.

43 Cha HJ, Lee HH, Chae SW, Cho WJ, Kim YM, Choi HJ, Choi DH, Jung SW, Min YJ, Lee BJ, Park SE, Park JW: Tristetraprolin downregulates the expression of both vegf and cox-2 in human colon cancer. Hepatogastroenterology 2011;58:790-795.

-44 Marderosian M, Sharma A, Funk AP, Vartanian R, Masri J, Jo OD, Gera JF: Tristetraprolin regulates cyclin d1 and c-myc mrna stability in response to rapamycin in an akt-dependent manner via p38 mapk signaling. Oncogene 2006;25:6277-6290.

-45 Selmi T, Martello A, Vignudelli T, Ferrari E, Grande A, Gemelli C, Salomoni P, Ferrari S, Zanocco-Marani T: Zfp36 expression impairs glioblastoma cell lines viability and invasiveness by targeting multiple signal transduction pathways. Cell Cycle 2012;11:1977-1987.

46 Xia G, Wang H, Song Z, Meng Q Huang X, Huang X: Gambogic acid sensitizes gemcitabine efficacy in pancreatic cancer by reducing the expression of ribonucleotide reductase subunit-m2 (rrm2). J Exp Clin Cancer Res 2017;36:107. 


\section{Cellular Physiology Cell Physiol Biochem 2018;46:829-846 \begin{tabular}{l|l} 
DOI: 10.1159/000488740 & O 2018 The Author(s). Published by S. Karger AG, Basel \\
www.karger.com/cpb
\end{tabular} \\ Wei et al.: GA Kills Colorectal Cancer Stem Cells}

-47 Wei F, Rong XX, Xie RY, Jia LT, Wang HY, Qin YJ, Chen L, Shen HF, Lin XL, Yang J, Yang S, Hao WC, Chen Y, Xiao SJ, Zhou HR, Lin TY, Chen YS, Sun Y, Yao KT, Xiao D: Cytokine-induced killer cells efficiently kill stem-like cancer cells of nasopharyngeal carcinoma via the nkg2d-ligands recognition. Oncotarget 2015;6:3502335039.

48 Rong XX, Wei F, Lin XL, Qin YJ, Chen L, Wang HY, Shen HF, Jia LT, Xie RY, Lin TY, Hao WC, Yang J, Yang S, Cheng YS, Huang WH, Li AM, Sun Y, Luo RC, Xiao D: Recognition and killing of cancer stem-like cell population in hepatocellular carcinoma cells by cytokine-induced killer cells via nkg2d-ligands recognition. Oncoimmunology 2016;5:e1086060.

49 Cai L, Qiu N, Xiang M, Tong R, Yan J, He L, Shi J, Chen T, Wen J, Wang W, Chen L: Improving aqueous solubility and antitumor effects by nanosized gambogic acid-mpeg(2)(0)(0)(0) micelles. Int J Nanomedicine 2014;9:243-255.

50 Yin D, Yang Y, Cai H, Wang F, Peng D, He L: Gambogic acid-loaded electrosprayed particles for site-specific treatment of hepatocellular carcinoma. Mol Pharm 2014;11:4107-4117.

-51 Ma J, Zhang Y, Tang K, Zhang H, Yin X, Li Y, Xu P, Sun Y, Ma R, Ji T, Chen J, Zhang S, Zhang T, Luo S, Jin Y, Luo X, Li C, Gong H, Long Z, Lu J, Hu Z, Cao X, Wang N, Yang X, Huang B: Reversing drug resistance of soft tumorrepopulating cells by tumor cell-derived chemotherapeutic microparticles. Cell Res 2016;26:713-727.

52 Zhang Z, Qian H, Yang M, Li R, Hu J, Li L, Yu L, Liu B, Qian X: Gambogic acid-loaded biomimetic nanoparticles in colorectal cancer treatment. Int J Nanomedicine 2017;12:1593-1605. 